\title{
Assesment of Father's Involvement in Child Care Development
}

\author{
Kumari Sonali* \& Mishra Sunita**, \\ MSc. Student* \& Professor**Dean and Head \\ Department of Human Development \& Family Studies \\ School for Home Sciences, Babasaheb Bhimrao Ambedkar University, Lucknow-226025
}

\begin{abstract}
Fatherhood is the act of being a father, as opposed to merely "fathering" a child. The father has an important potential role at each developmental stage that his children pass through. During pregnancy and birth, the father-to-be plays crucial roles in the transition of the family. Fathers discipline with respect and with love, the goal being to help socialize their children in positive ways. Good fathers set limits and are firmThe present study was undertaken to assess the Impact of father's involvement in child care and development. The study was based upon the sample 120 respondents in South City, RajniKhand, RuchiKhand and Banglabajar were selected purposively from semi urban area in Lucknow city in U.P Interview schedule as used for data collection and Purposive sampling method was used for sample selection. F test and Chi square analysis was used for data analysis. . The result revealed that father's education and occupation had highly significant impact on father's involvement in child care and development.
\end{abstract}

Keywords:- fathers involvement, child care and development

\section{Introduction :-}

"A child without a father is like a house without a roof". A popular Budhist saying. father who are more involved in infant care giving have infants with greater cognitive development. Fathers involved with their children become high in level in their daily activities; they show higher level of sociability and high level of school performance. Psychologist have claimed father's responsibility is the most important for a child's developmental wellbeing (Russel-1983). Fathers have a critical role play in ensuring positive outcomes for their children. There is consistent evidence that father's interest and involvement in their children's learning (which was measured in terms of interest in education, outings and reading to the child ) is statistically associated with better education outcomes (controlling for a wide variety of to their influencing factors). These out comes included better exam results, a higher level of educational qualifications, greater progress at school, higher level of education qualifications greater progress at school, higher educational expectations more positive attitude and better behavior at school. Fathers tend to challenge children to try out and explore, acquire experience and become more independent. This might be one of the reasons that they influence their children's competence. Challenged children are more likely to develop problem-solving skills. Father are involved in their children's lives in a multitude of ways that go beyond the traditional roles of "economic provider" and "playmate". However ,few studies that include fathers tap all aspects of fathers involvement in children's lives. Furthermore, the quality of father- child interactions is not as frequently studied or as well understood as is the quantity of father-child contact. Children with involved, caring fathers have better educational outcomes. A number of studies suggest that fathers who are involved, nurturing, and playful with their infants have children with higher IQs, as well as better linguistic and cognitive capacities. Toddlers with involved fathers go on to start school with higher levels of academic readiness. They are more patient and can handle the stresses and frustrations associated with schooling more readily than children with less involved fathers.

The influence of a father's involvement on academic achievement extends into adolescence and young adulthood. Numerous studies find that an active and nurturing style of fathering is associated with better verbal skills, intellectual functioning, and academic achievement among adolescents. For instance, a 2001 U.S. Department of Education study found that highly involved biological fathers had children who were 43 percent more likely than other children to earn mostly As and 33 percent less likely than other children to repeat a grade.

\section{OBJECTIVE}

1. To impact of father's occupation involvement in child care and development.

2. To influence father's education in child care and development.

\section{Methodology}

The present study was conducted on school going children in the year 2010. The main area of study was sarda nagar selected South City, Rajni Khand, Ruchi Khand and Bangla Bazar. A total of 120 respondents were selected for the study. Purposive sapling method was used for sample selection and interview schedule was 
used for data collection. After data collection, the data were tabulated in Microsoft excel and analysis was done by using frequency, percentage and f-test through SPSS $\left(20^{\text {th }}\right.$ version $)$.

\section{Research Finding And Discussion} sub heads.

The results of the present study as well as relevant discussions have been presented under following

Figure 1: Distribution of respondents fathers according to their education

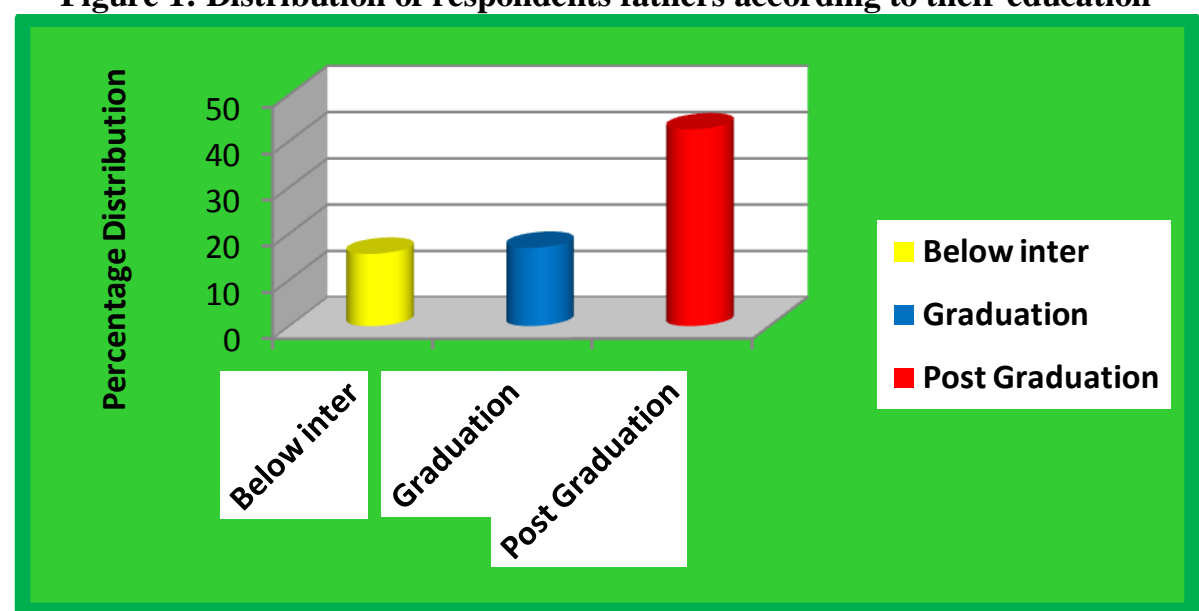

The above graph showed that (15.6\%) respondent of fathers were below inter where as (16.9\%) respondent fathers were graduate and $(42.5 \%)$ respondent fathers was post graduate.

Figure 1: Distribution of respondents fathers according to their occupation.

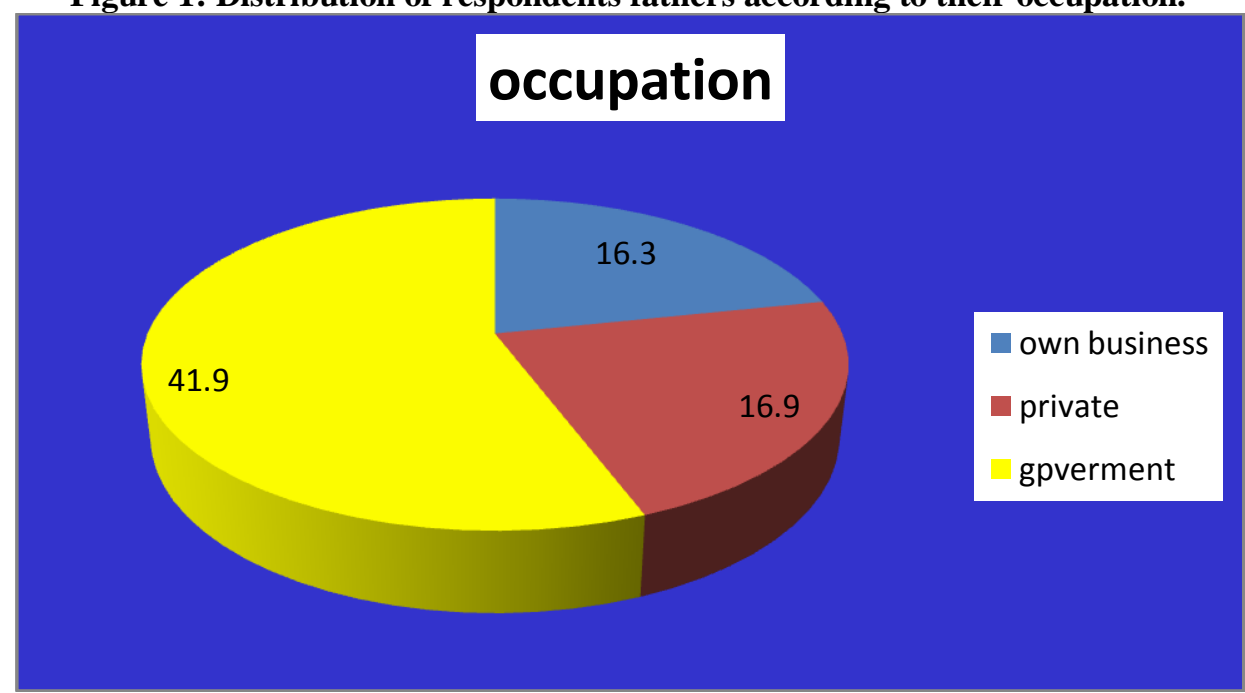

Fig. 2 reveals showed that own business $(16.5 \%)$ fathers were working (16.9\%) fathers were working in private and $(41.9 \%)$ fathers were working in government.

Table 1:-Assessment of mean, SD and $f$ value of influence of fathers education in child care and development.

\begin{tabular}{|c|c|c|c|c|c|c|c|}
\hline \multicolumn{8}{|c|}{ Education } \\
\hline \multicolumn{2}{|c|}{ Below inter } & \multicolumn{2}{|c|}{ Graduation } & \multicolumn{2}{|c|}{ Post graduation } & F test & P value \\
\hline M & SD & $\mathrm{M}$ & SD & M & SD & 10.441 & $.000 * * *$ \\
\hline 23.00 & 4.699 & 26.96 & 4.965 & 28.01 & 4.596 & & \\
\hline
\end{tabular}

(Figures in parentheses indicate percentages)

The result revealed that, highly significant difference was found between education about involvement of father's in child care and development, which means that involvement in child care and development was dependent or influenced by education. 
Table no-2 Assessment of mean, SD and $f$ value of influence of fathers occupation in child care and development.

\begin{tabular}{|c|c|c|c|c|c|c|c|}
\hline \multicolumn{8}{|c|}{ Occupation } \\
\hline \multicolumn{2}{|c|}{ Own business } & \multicolumn{2}{|c|}{ Private } & \multicolumn{2}{|c|}{ Government } & F-test & P-value \\
\hline $\mathrm{M}$ & SD & $\mathrm{M}$ & SD & $\mathrm{M}$ & SD & \multirow{2}{*}{8.153} & \multirow{2}{*}{$0.00^{* *}$} \\
\hline 24.08 & 4.049 & 25.56 & 5.866 & 28.24 & 4.556 & & \\
\hline
\end{tabular}

. ( $\mathrm{P}<0.01, * *$ highly significant $)$

The above table showed that high mean value is government occupation of the respondents fathers mean value 28.24 followed by private occupation of the respondents fathers mean value is the 25.56 and own business of the respondents fathers mean value 24.08 so that f-test was found highly significant differences between occupation of the respondent's fathers and their effect of father's involvement in child care and development. This means that involvement in child care and development or influenced by father's occupation.

\section{Conclusion}

It was observed in the study that parental education and occupation play very prominent role in personality enrichment of children and education parents were more conscious about their children behavior and socio emotional development. It was statistically proved that father's with better qualification were expected to develop the personality of their children on modern life. The relationship between education and occupation of father and attitude of child care and development was examined. The significant value of f-test depicts that as educational level of father increase there might be more favorable attitudes of children towards pattern of fathers involvement in child care and development. This shows that there is an association between dependent and independent variables.

\section{Literature Cited}

[1]. Russel (1983).Responsibility is the most important for a child's developmental wellbeing

[2]. Mishra.S, and Dayal.O (2012). "Impact of father's education on personality development of school going children". International Research Journal Lab to Land,4: 182-186

[3]. Mishra.S and Dayal O (2012). Impact of family size and gender on personality of school going children among low income group families. Asian journal Home Science: An International Referred Journal, , 7 (2): 544-547

[4]. Mishra.S and Prabha S (2012).The parent involvement in their children activities. Asian journal Home Science: An International Referred Journal, 70 (2):551-553

[5]. http://msuextension.org/publications/HomeHealthandFamily/MT200008HR.pdf

[6]. http://www.civitas.org.uk/hwu/fathers.php 